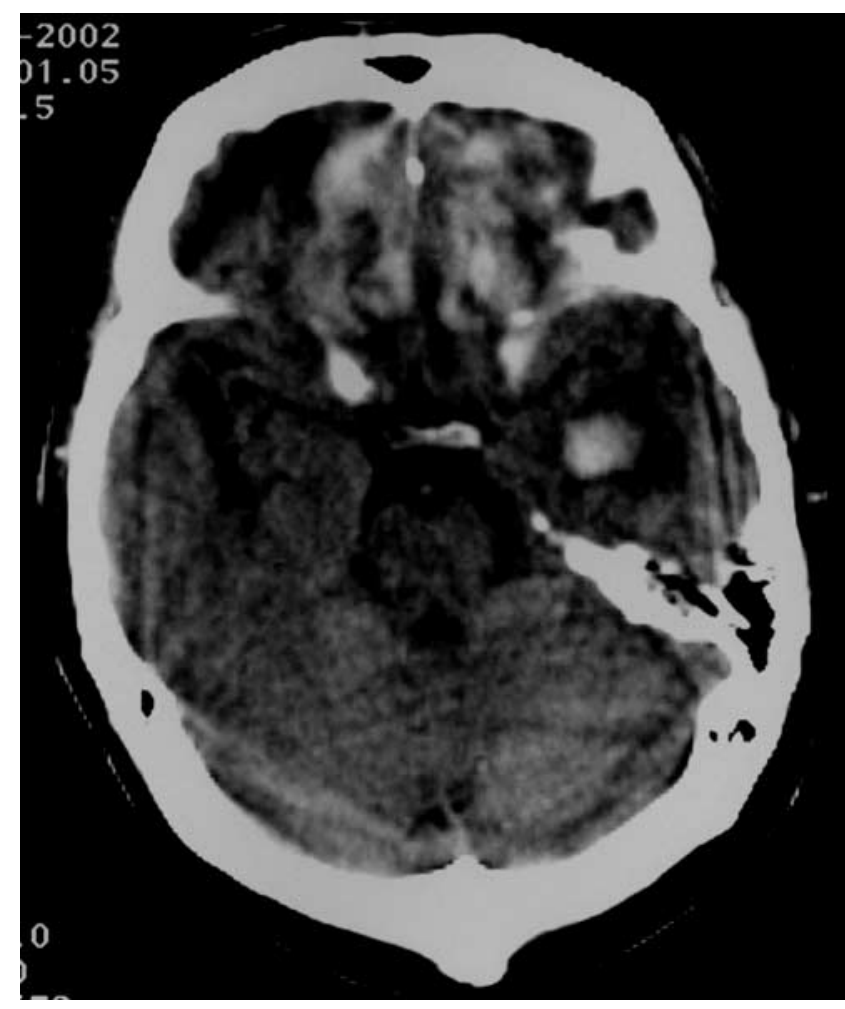

Figure 2 CT scan showing worsening of bifrontal haemorrhage

be used for prophylaxis if started 24 hours or more after the acute admission.

In the case described here, cerebral haemorrhage worsened when a low-molecular-weight heparin was given a week after the original injury -and there were no apparent aggravating factors such as clotting derangements or sepsis. Although the aim was therapeutic rather than prophylactic (pulmonary embolism was suspected), the case does illustrate the hazards of these agents. Most of the published evidence on anticoagulation in headinjured patients is retrospective and thus insecure. For prophylaxis at least, until better evidence emerges, we would favour mechanical measures (antiembolism stockings, intermittent calf compression, physiotherapy) rather than heparins.

\section{REFERENCES}

1 Karni A, Holtzman R, Bass $T$, et al. Traumatic head injury in the anticoagulated elderly patients: a lethal combination. Am Surg 2001;67: 1098-100

2 Nurmohamed MT, Van Riel AM, Henkens CM. Low molecular weight heparin and compression stockings in the prevention of venous thromboembolism in neurosurgery. Thrombosis Haemostasis 1996;75: 233-8

3 Constantini S, Kaner A, Friedman A, et al. Study of perioperative minidose heparin in patients undergoing brain tumour surgery: a prospective, randomised, double blind study. J Neurosurg 2001;94: 918-21

4 Norwood SH, McAuley CE, Berne JD, et al. Prospective evaluation of enoxaparin prophylactics for venous thrombo-embolism in patients with intracranial hemorrhagic injuries. Arch Surg 2002;137: 696-701

\section{Atypical melanoma}

\author{
Susannah Baron ChB MRCP \\ Victoria Goulden MD FRCP Graeme Stables MD FRCP
}

The incidence of malignant melanoma continues to rise in many parts of the world. A seven-point checklist for moles is useful in identifying lesions that need to be excised. The three major signs are change in shape, change in size and change in colour; the four minor signs are over $7 \mathrm{~mm}$ in diameter, inflammation, crusting or bleeding and minor irritation or itch. Lesions with any major signs or three minor signs are suspicious of melanoma. ${ }^{1}$ Unfortunately malignant melanoma can present atypically.

\title{
CASE HISTORIES
}

\section{Case 1}

A woman of 40 sought advice about an erythematous scaly plaque on her left arm, $0.6 \times 0.4 \mathrm{~cm}$, which had appeared 3 years earlier (Figure 1). The lesion had gradually increased in size and become more erythematous over the preceding three months. She had experienced blistering sunburn in childhood but there was no family history of skin cancer. The differential diagnosis was Bowen's disease (intraepithelial carcinoma) or an irritated seborrhoeic wart, but a punch biopsy showed in-situ melanoma. The melanoma was excised with a $5 \mathrm{~mm}$ margin and histological examination confirmed lack of dermal invasion. The patient was apparently disease-free twelve months later.

\section{CASE 2}

A woman aged 79 had first noticed the lesion on her cheek 2 years before, after a minor trauma. It had gradually enlarged. On examination she had an infiltrated plaque with a pearly edge; the diameter was about $3.3 \mathrm{~cm}$ but the edges were indistinct. Directly below her eye were two pigmented macules and there were several pigmented nodules within the plaque (Figure 2). The clinical diagnosis was a pigmented basal cell carcinoma but urgent biopsy revealed the lesion to be a superficial spreading malignant melanoma with both vertical and horizontal growth phases. The maximum thickness of the tumour on biopsy was $4.2 \mathrm{~mm}$. The melanoma was widely excised by the plastic surgeons and the area was reconstructed with a skin graft. On histological examination the Breslow thickness was

General Infirmary at Leeds, LS1 3EX, UK

Correspondence to: Dr S Baron

E-mail: Susannah.baron@ntlworld.com 


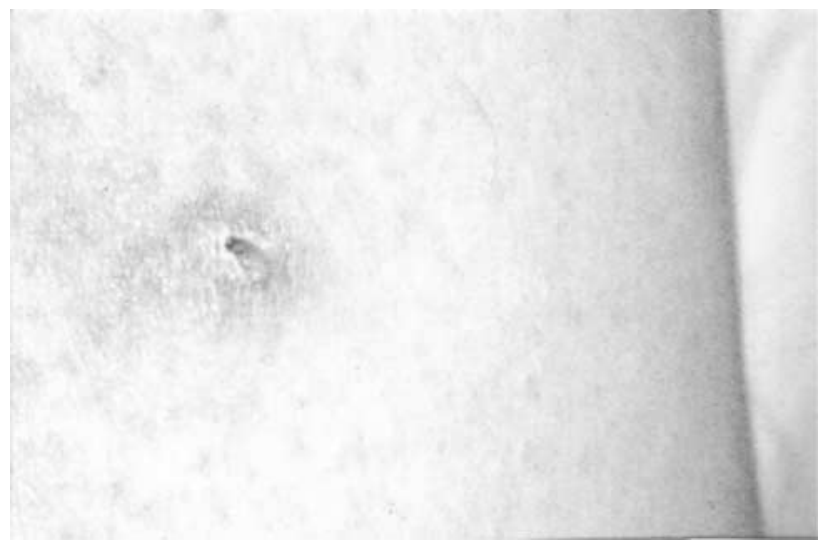

Figure 1 Lesion in patient 1

$6.1 \mathrm{~mm}$. There were no signs of recurrent disease eighteen months later.

\section{CASE 3}

A woman of 50 had 3 years earlier noticed a raised skincoloured nodule on her right lower shin, which was diagnosed by her general practitioner as a dermatofibroma. In the past twelve months it had increased in size and bled,

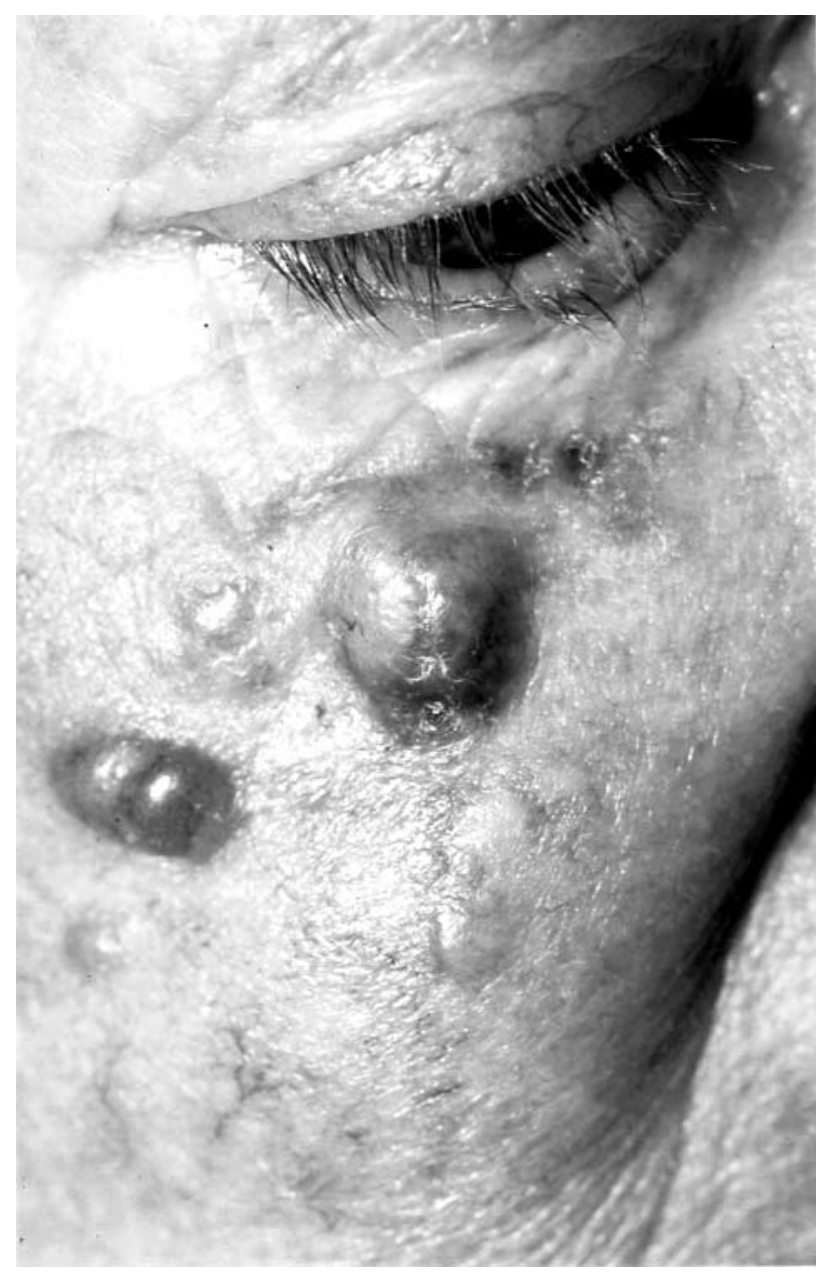

Figure 2 Lesion in patient 2 spontaneously, prompting a referral to the dermatology department. On examination the lesion was domed, flesh coloured, and firm, $1 \mathrm{~cm}$ in diameter, with a small area of irregular brown pigmentation around one lateral border (Figure 3). Because of the macular pigmentation an incisional biopsy was performed, which was reported as showing a benign intradermal naevus. The appearance remained of clinical concern, so the lesion was excised by the plastic surgeons in a procedure requiring a full-thickness skin graft. Histological examination of the entire specimen showed a melanoma in vertical growth phase with a Breslow thickness of $2.5 \mathrm{~mm}$, extending to Clark's level 4. Unfortunately five months after excision she developed enlarged inguinal lymph nodes, positive for metastatic melanoma. She entered a clinical trial of interferon-alpha.

\section{CASE 4}

At age 41 a woman was referred by her general practitioner with an enlarging, discharging ulcerated lesion at the base of her right third toe; it had appeared six months earlier after a sandfly bite in Belize (Figure 4). The history and appearance was suggestive of cutaneous leishmaniasis and a biopsy was taken. This showed invasive malignant melanoma with a Breslow thickness of $4 \mathrm{~mm}$. The melanoma was widely excised with $2 \mathrm{~cm}$ margins and the area was reconstructed with a split skin graft. Histological examination confirmed a superficial spreading malignant melanoma with a predominant ulcerated nodular component of maximum Breslow thickness $4.9 \mathrm{~mm}$ (Clark's level 5). A wider excision was then performed with amputation of the third and fourth toes. A year later, melanoma was found in an enlarged right inguinal lymph node and had metastasized to lungs and liver. Despite chemotherapy she died two months later.

\section{COMMENT}

Early detection of malignant melanoma is essential since survival prospects are strongly related to tumour (Breslow) thickness at the time of diagnosis. ${ }^{2}$ The Breslow thickness, measured on histological examination, is the distance between the overlying epidermal granular layer and the deepest invasive area of the primary lesion. ${ }^{3}$ For lesions of Breslow thickness $<1 \mathrm{~mm}$ the recommended excision margin is $1 \mathrm{~cm}$ and 5-year survival is 95-100\%. For Breslow thickness $>4 \mathrm{~mm}$ the recommended margin is $2-3 \mathrm{~cm}$ and 5 -year survival is about 50\%. The levels of invasion into the dermis introduced by Clark et al. ${ }^{4}$ are a similar prognostic indicator related to penetration by the primary lesion, level 5 signifying invasion into fat.

About 2\% of all melanomas are amelanotic, though on close inspection most amelanotic tumours do show pigmentation of the adjacent skin, as in case 3. Amelanotic melanoma is the subtype most often reported as simulating 


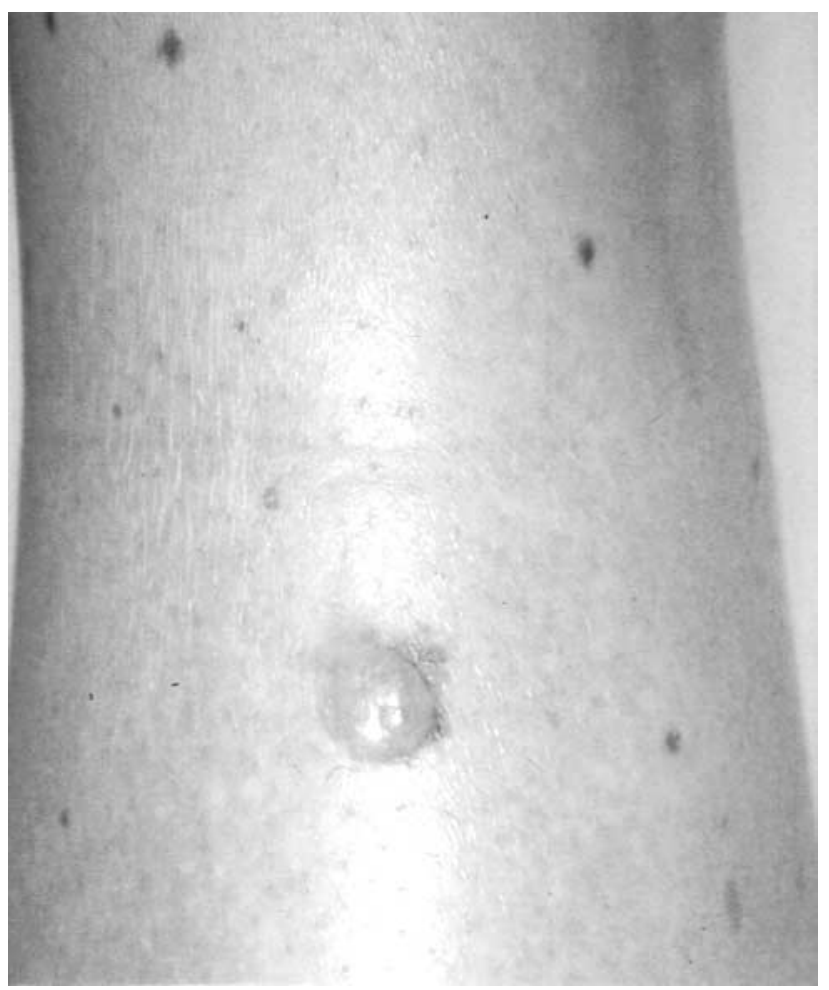

Figure 3 Lesion in patient 3

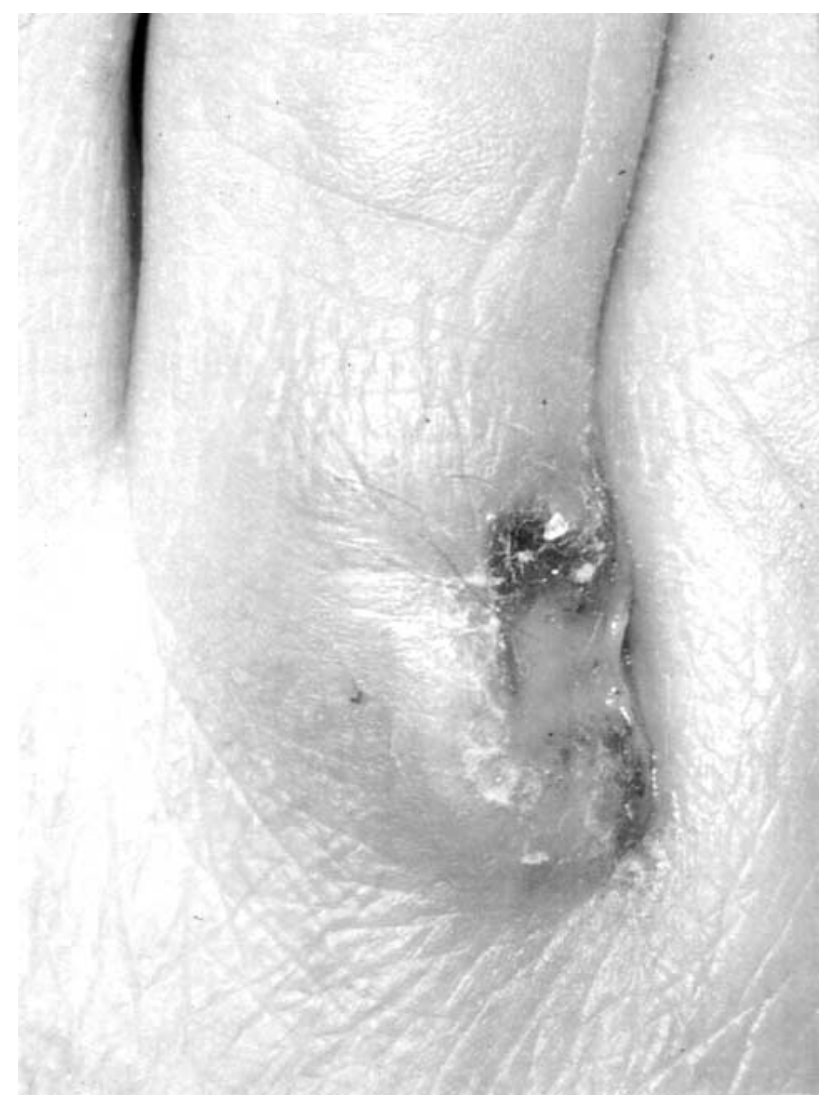

Figure 4 Lesion in patient 4 other cutaneous lesions, but even pigmented melanomas are commonly misdiagnosed - especially as melanocytic naevus, basal cell carcinoma, seborrhoeic keratosis or lentigo. ${ }^{5}$

In a study comparing the ability of general practitioners and dermatologists to discriminate pigmented lesions the general practitioners made an exact diagnosis of melanoma in $50 \%$ of the cases compared with the dermatologists' $84 \%{ }^{6}$ Any changing or atypical mole or non-healing skin lesion should be referred urgently to a dermatologist or to a surgeon with a special interest in pigmented lesions.

\section{REFERENCES}

1 Du Vivier AWP, Williams HC, Brett JV, Higgens EM. How do malignant melanomas present and does this correlate with the sevenpoint check-list? Clin Exp Dermatol 1991;16:344-7

2 MacKie RM, Hole D, Hunter JA, et al. Cutaneous malignant melanoma in Scotland: incidence, survival, and mortality, 1979-94. BMJ 1997;315:111-21

3 Breslow A. Thickness, cross-sectional areas and depth of invasion in the prognosis of cutaneous melanoma. Ann Surg 1970;172:902-8

4 Clark WH, Elder D, Guerry D, et al. Model predicting survival in stage I melanoma based on tumour progression. J Natl Cancer Inst 1989;87:1893-904

5 Witheiler DD, Cockerell CJ. Histologic features and sensitivity of diagnosis of clinically unsuspected cutaneous melanoma. Am J Dermatopathol 1991;13:551-6

6 Brochez L, Verhaeghe E, Bleyen L, et al. Diagnostic ability of general practitioners and dermatologists in discriminating pigmented skin lesions. J Am Acad Dermatol 2001;44:979-85

\section{Acute haemolytic anaemia after inhalation of amyl nitrite}

Tracey D Graves BSc MRCP Sheena Mitchell FRCP

Haemolytic anaemia can be caused by drugs, including some used for recreational purposes.

\section{CASE HISTORY}

An Afro-Caribbean man aged 35 was transferred from a psychiatric unit where for six months he had been receiving inpatient care for schizophrenia. For the past two days he had felt generally unwell with fevers. He had passed red urine and his sclerae had become yellow. There was no associated abdominal pain and his stools had been of normal

Care of the Older Person, Whittington Hospital, London N19 5NF, UK

E-mail: Sheena.Mitchell@whittington.nhs.uk 